\title{
金属材料のキャビテーション壊食挙動の定式化*
}

\author{
服 部 修 次*1, 前 田 浩 平*2
}

\section{Formulation of Cavitation Erosion Behavior of Metals}

\author{
Shuji HATTORI*3 and Kohei MAEDA \\ ${ }^{* 3}$ Department of Mechanical Engineering, University of Fukui, \\ 3-9-1 Bunkyo, Fukui-shi, Fukui, 910-8507 Japan
}

\begin{abstract}
The authors previously reported that the variation in volume loss rate during cavitation erosion process could be expressed by a logistic curve. In this study, the validity of this model was examined for the various materials such as pure aluminum, carbon steels, stainless steels and cobalt alloys, etc. The MDE (mean depth of erosion) $d$ with exposure time was expressed by three parameters $\alpha, \beta$ and $c$ in the following equation. $d=(\alpha / \beta) t-(1 / \beta) \ln (1+c) /\left(1+c e^{-\alpha t}\right)$. The parameter $\alpha, \beta$ and $c$ were derived from the relation of the incubation period and the slope of maximum rate stage in MDE curve. It was concluded that the calculation based on this model corresponds well to MDE curve due to cavitation in various materials, test conditions and test methods.
\end{abstract}

Key Words: Cavitation Erosion, Iron and Steel, Nonferrous Metal, Erosion, Cavitation, Modeling, Logistic Curve

\section{1. 緒}

キャビテーション壊食は, 気泡崩壊時の衝撃力が材 料表面に繰返し作用して材料表面が塑性変形し, その 後き裂が発生, 進展して損傷する疲労破壊現象であ る. 壊食量を予測するためには, 壊食量の時間的変化 を定量的に記述する必要がある. 加藤(1) は流水中の 水中翼モデルを使用して気泡崩壊時に発生するエネル ギーから壊食量を予測する方法を提案し, Rao-Buckley ${ }^{(2)}$ は回転円板法における長時間予測モデルや解析 方法を報告している。しかし, 両報告とも, 提案され ている手法が他の試験方法に適用できるかどうか明ら かにされていない. Karimi ら(3)〜(5) は, 材料の機械的 性質 (耐力, 破断応力, 加工硬化係数など) と気泡崩壊 圧の頻度分布を用いた壊食モデルから質量減少量の時 間的変化を速度期と定常期に分けて表示できるとして いる.しかし，この方法では壊食の全期間を通じて一 つの式で表すことができない欠点がある.

著者ら ${ }^{(6)}$ は先に, キャビテーションによる壊食過程

* 原稿受付 2004 年 12 月 10 日.

*1 正員, 福井大学工学部 ( 910-8507 福井市文京 3-9-1).

*2 福井大学大学院工学研究科.

E-mail : hattori@mech.fukui-ac.jp
が全過程を通じて三つのパラメータを用いたロジステ イック曲線で表示できることを報告した。しかし，前 報(6)では, アルミナセラミックスおよび純銅の限られ た試験材料について検討し, 試験条件としては, 磁わ い振動装置の全振幅 $50 \mu \mathrm{m}$ の場合のみであった.

本研究では, 前報(6)で提案した壊食過程の表示式 で，パラメータの数を少なくする方策を検討した。ま た, こうした方法で種々の材料, 試験方法, 試験条件 のキャビテーション壊食過程を表示できるかどうかに ついても検討した.

\section{2. 壊食挙動の定式化}

図 1 は前報(6) で報告した壊食過程を表すモデル図 で, 図 1( a )〜 ( c ) は壊食痕の增殖過程を示している. 図 1 に示すように, 壊食痕は先に存在する気孔を核と して増加するので, 壊食痕の数を $p$ とおくと単位時間 当たりの壊食痕数の変化は次式で表示できる.

$$
\mathrm{d} p / \mathrm{d} t=\alpha p \text {. }
$$

このとき, 壊食痕 1 個の体積がほほ同じであると仮 定すると単位時間当たりの体積減少速度 $u$ の変化は 次式で表すことができる。

$$
\mathrm{d} u / \mathrm{d} t=\alpha u
$$

一方, 合体過程における壊食速度の変化がピットど 
うしの組合せの数に比例し, $u$ の二次式で与えられる とすると,

$$
\mathrm{d} u / \mathrm{d} t=-\beta u^{2}
$$

したがって, 単位時間当たりの体積減少速度の変化は 式(4)で与えられる.

$$
\mathrm{d} u / \mathrm{d} t=\alpha u-\beta u^{2}
$$

上式を初期体積減少速度 $u=u_{0}$ を基に解けば体積減 少速度は

$$
u=\frac{\alpha}{\beta} \frac{1}{1+c e^{-\alpha t}}
$$

となる.ただし，

$$
c=\frac{\alpha}{\beta} \frac{1}{u_{0}}-1
$$

である。累積体積減少量 $V$ は式 (5)を積分し, 初期 体積減少量 $V_{0}=0$ とすると,

$$
V=\int_{0}^{t} u(t) \mathrm{d} t=\frac{\alpha}{\beta} t-\frac{1}{\beta} \ln \frac{1+c}{1+c e^{-\alpha t}}
$$

で与えられる。式 ( 5 ) は体積減少速度が一定時間の潜 伏期ののち急増し，一定値に漸近する曲線を表し，式 （７）は初期に潜伏期を示したのちに一定の速度で増加 する累積体積減少量曲線を示す(6). ここで， $\alpha$ は単位 時間当たりの壊食痕の増加係数(壊食痕の増殖のしゃ すさ), $\beta$ は単位時間当たりの壊食痕どうしの合体係 数, $\alpha / \beta$ は体積減少速度曲線のピーク值である。 $\operatorname{MDE}$ (Mean Depth of Erosion, 平均壊食深さ)は累積 体積減少量を試験面積 $\left(201 \mathrm{~mm}^{2}\right)$ で除したものである から時間変化に対する曲線の挙動は変わらない.した がって, MDEを $d$ とおくと

$$
d=\frac{\alpha}{\beta} t-\frac{1}{\beta} \ln \frac{1+c}{1+c e^{-\alpha t}}
$$

で表示できる， $\alpha / \beta$ は, MDE曲線の最大速度期の直 線部のこう配を示している.また, 式 $(7$ ) と式( 8 )の パラメータの次元は異なっている.

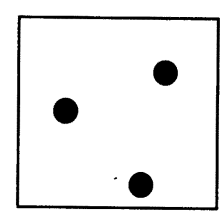

(a)

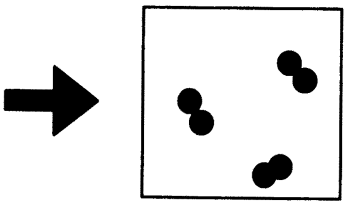

(b)

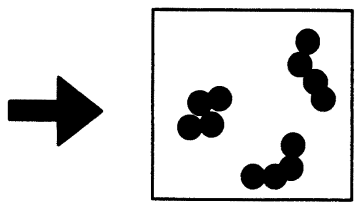

(c)

Fig. 1 Growth model of pits

\section{3. 試験材料および試験方法}

本研究で解析する壊食試験結果の多くは, これまで 本研究室で試験してきたものを用いたが，一部は今回

\begin{tabular}{|c|c|c|c|c|c|c|c|c|c|c|}
\hline & $\mathrm{Si}$ & $\mathrm{Fe}$ & $\mathrm{Cu}$ & $\mathrm{Mn}$ & $\mathrm{Mg}$ & $\mathrm{Cr}$ & $\mathrm{Zn}$ & v & $\mathrm{Ti}$ & Al \\
\hline A1050 & 0.09 & 0.14 & 0.01 & 0.01 & 0.01 & 0 & 0.01 & - & 0.01 & Bal \\
\hline A1070 & 0.09 & 0.15 & 0.01 & 0.01 & 0.01 & 0 & 0 & 0.01 & 0.01 & Bal \\
\hline $\mathrm{C}_{1020}$ & $\cdot$ & - & 99.96 & - & - & - & - & - & - & - \\
\hline \multirow[t]{2}{*}{ C1100 } & - & - & 99.90 & - & - & - & - & - & - & - \\
\hline & C & $\mathrm{Si}$ & $\mathrm{Mn}$ & $\mathbf{P}$ & $s$ & $\mathrm{Cu}$ & $\mathrm{Cr}$ & $\mathrm{Ni}$ & $\mathrm{Fe}$ & \\
\hline S15C & 0.15 & 0.25 & 0.47 & 0.015 & 0.013 & 0.14 & 0.18 & 0.04 & Bal & \\
\hline S55C & 0.54 & 0.27 & 0.82 & 0.016 & 0.017 & 0.14 & 0.18 & 0.04 & Bal & \\
\hline \multirow{2}{*}{ SS400 } & 0.14 & 0.25 & 0.46 & 0.21 & 0.013 & - & - & - & - & \\
\hline & C & $\mathrm{Si}$ & $M n$ & $\mathbf{P}$ & $\mathrm{s}$ & $\mathrm{Pb}$ & & & & \\
\hline \multirow[t]{2}{*}{ SK95 } & 0.94 & 0.23 & 0.73 & 0.027 & 0.063 & 0.12 & & & & \\
\hline & $C$ & $\mathrm{Si}$ & $\mathrm{Mn}$ & $\mathbf{P}$ & s & $\mathrm{Ni}$ & $\mathrm{Cr}$ & Mo & & \\
\hline \multirow[t]{2}{*}{$\mathrm{FC} 200$} & 3.38 & 2.19 & 0.58 & 0.021 & 0.016 & $\therefore$ & 0.038 & - & & \\
\hline & C & $\mathrm{Si}$ & $\mathrm{Mn}$ & $\mathbf{P}$ & $s$ & $\mathrm{Cr}$ & $\mathrm{Ni}$ & Mo & $\mathrm{Cu}$ & \\
\hline SUS304 & 0.05 & 0.37 & 1.19 & 0.026 & 0.004 & 18.17 & 8.16 & - & - & \\
\hline SUS316 & 0.05 & 0.24 & 1.36 & 0.033 & 0.027 & 16.94 & 10.21 & 2.06 & - & \\
\hline \multirow[t]{2}{*}{ SUS630 } & 0.05 & 0.3 & 0.89 & 0.039 & 0.004 & 15.66 & 4.29 & - & 3.35 & \\
\hline & $C$ & Si & $\mathrm{Mn}$ & $\mathbf{P}$ & $\mathbf{s}$ & $\mathrm{Ni}$ & $\mathrm{Cr}$ & Mo & & \\
\hline scs3 & 0.1 & 0.73 & 0.55 & 0.037 & 0.005 & 1.38 & 12.75 & 0.7 & & \\
\hline Scs5 & 0.06 & 1 & 1 & 0.04 & 0.04 & 4 & 13.5 & - & & \\
\hline \multirow[t]{2}{*}{ SCS16 } & 0.03 & 1.5 & 2 & 0.04 & 0.04 & 14 & 18.5 & 2.5 & & \\
\hline & Co & $\mathrm{Fe}$ & $\mathrm{Cr}$ & $w$ & $\mathrm{Ni}$ & C & Mn & $\mathrm{Si}$ & & \\
\hline Pure-Co & 100 & - & - & - & - & - & - & - & & \\
\hline $\mathrm{Co}-2 \mathrm{Wt} \% \mathrm{Fe}$ & 98 & 2 & - & - & - & - & - & - & & \\
\hline $\mathrm{Co}-4 \mathrm{~W}+\% \mathrm{Fe}$ & 96 & 4 & - & - & - & - & - & - & & \\
\hline Co-10Wi\%Fe & 90 & 10 & - & - & - & - & - & - & & \\
\hline
\end{tabular}
追加試験を行った. 試験材料としては, アルミニウム, 純銅, 炭素鋼, 炭素工具鋼, 鋳鉄, ステンレス鋼, ステ ンレス鋳鋼，コバルト合金である，供試材料の化学成 分, 機械的性質を表 1,2 に示す。また, 供試材料は,

Table 1 Chemical composition [mass.\%]

Table 2 Mechanical properties

\begin{tabular}{|c|c|c|c|c|c|}
\hline Material & $\begin{array}{c}\text { Density } \\
\mathrm{mg} / \mathrm{mm}^{3}\end{array}$ & $\begin{array}{c}\text { Modulus of } \\
\text { elasticity } \\
\text { GPa }\end{array}$ & $\begin{array}{c}\text { Tensile } \\
\text { strength } \\
\text { MPa }\end{array}$ & $\begin{array}{c}\text { Vickers } \\
\text { hardness } \\
\text { HV }\end{array}$ & $\begin{array}{c}\text { Rockwell } \\
\text { hardness } \\
\text { HRC }\end{array}$ \\
\hline A1050 & 2.71 & 71 & 178 & 33 & - \\
\hline A1070 & 2.71 & 73 & 99 & 32 & - \\
\hline C1020 & 8.96 & 115 & 326 & 90 & - \\
\hline C1100 & 8.96 & 129 & 328 & 103 & - \\
\hline S15C & 7.87 & 206 & 388 & 151 & - \\
\hline S55C & 7.87 & 204 & 701 & 238 & - \\
\hline SS400 & 7.80 & 210 & 442 & 143 & - \\
\hline SK95 & 7.80 & - & 655 & - & 52.3 \\
\hline FC200 & 7.10 & 97 & - & 243 & - \\
\hline SUS304 & 7.98 & 200 & 618 & 209 & - \\
\hline SUS316 & 7.98 & 193 & 612 & 173 & - \\
\hline SUS630 & 7.80 & 206 & 892 & 330 & - \\
\hline SCS3 & 7.81 & 204 & 777 & 238 & - \\
\hline SCS5 & 7.86 & 204 & 849 & 260 & - \\
\hline SCS16 & 7.86 & 204 & 565 & 173 & - \\
\hline Pure-Co & 8.90 & 210 & 245 & 261 & - \\
\hline Co-2Wt\%Fe & 8.90 & 210 & - & 185 & - \\
\hline Co-4Wt\%Fe & 8.90 & 210 & - & 219 & - \\
\hline Co-10W4\%Fe & 8.90 & 210 & - & 165 & - \\
\hline & & & & & \\
\hline
\end{tabular}


エメリー紙で研磨したのち，鏡面になるまでバフ仕上 げされている。

キャビテーション壊食試験は, ASTM G 32-98(7) に基づく磁わい振動装置を用いた静置試験片法であ る(6). すなわち, 増幅ホーンの先端に耐エロージョン 性の良い直径 $16 \mathrm{~mm}$ のステンレス鋼(SUS 304)のデ イスクをねじ込んで取付けて振動させ，これと平行に すきま $1 \mathrm{~mm}$ 隔てて試験片を対向させて静置し，試験 面にエロージョンを発生させた. 試験面積はディスク 直径 $16 \mathrm{~mm}$ に対応する円形領域の $201 \mathrm{~mm}^{2}$ である. 振動子の共振周波数は $19.5 \mathrm{kHz}$ で, ディスク端面の 全振幅 (peak to peak) は主として $50 \mu \mathrm{m}$ 一定とした。 試験液はイオン交換水で, 液晶は恒温装置により $25 \pm$ $1^{\circ} \mathrm{C}$ に保持した。壊食量は所定時間ごとに精密天びん (感度 $0.01 \mathrm{mg}$ ) で質量隇少量を測定し, 密度と測定面 積で除した $\operatorname{MDE}$ (平均壊食深さ)で示した。 また, 試 験方法や試験条件を変更したときの壊食量を求めるた めに, 静置試験片法で共振周波数を $14.7 \mathrm{kHz}$, 振動 振幅を $40,60 \mu \mathrm{m}$ に変えて試験を行い, 振動試験片法 やキャビテーション噴流法でも試験を行った. 振動試

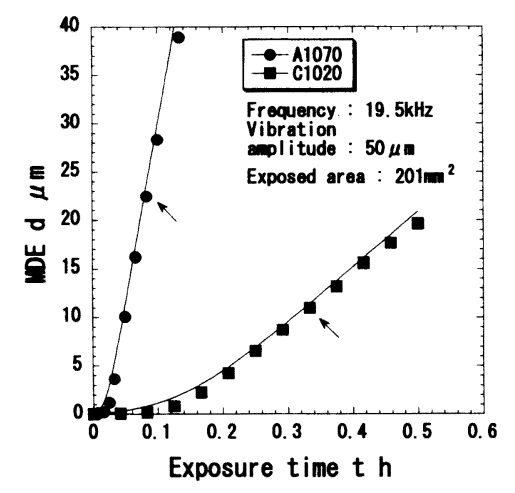

(a) Pure aluminum and copper

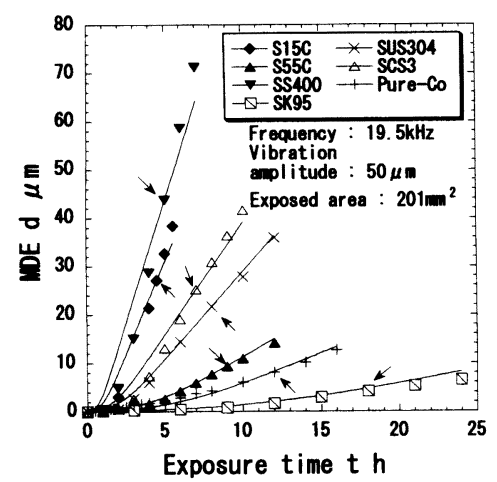

(b) Steels and Co-alloy

Fig. 2 MDE curves of various materials
験片法は磁わい振動装置のディスク部分を試験片とす る試験方法であり, キャビテーション噴流法は ASTM G 134-95(8) に準じて作成した試験水槽内を用 い上流圧 $P u=17.4 \mathrm{MPA}$, キャビテーション数 $\sigma=$ 0.025, スタンドオフ距離 $14 \mathrm{~mm}$ で行ったものであ る.

\section{4. 試験結果および考察}

$4 \cdot 1$ 壊食試験結果 各供試材料のキャビテーシ ヨン壊食試験をおこなったときの $\mathrm{MDE}$ (平均壊食深 さ)の実験点を図 2 に示す. 図 2 ではアルミニウムお よび純銅の壊食が他の材料よりも短時間で進行するた めに図を二つに分けて示した。図 2 の MDE 曲線では すべての材料において壊食速度の小さい潜伏期を経た のち, ほほ一定のこう配で増加する最大速度期に至る 傾向が認められる.また, 潜伏期が長い材料ほど最大 速度期における傾きが小さくなる. 図中の曲線および 矢印については $4 \cdot 2$ 節で述べる.

$4 \cdot 2$ パラメータ $\alpha, \beta, c$ の決定方法 緒言でも 述べたように, 著者ら ${ }^{(6)}$ は先に累積体積減少量曲線が 三つのパラメータ $\alpha, \beta, c$ を用いて表示できることを 提案した. 本研究ではパラメー夕数の減少について検 討した。

図 3 は MDE 曲線の模式図で, 最大速度期の延長線 と時間軸の交点を潜伏期 $t_{i}$ とし(7)，このときの $\mathrm{MDE}$ を $d_{i}$ とする. また, 最大速度期の任意の時間 $t_{0}$ のと きの MDEを $d_{0}$ とする.

式 ( 8 ) を再記すると

$$
d=\frac{\alpha}{\beta} t-\frac{1}{\beta} \ln \frac{1+c}{1+c e^{-\alpha t}}
$$

である.以下では， $t_{0}$ と $d_{0}$ が与えられたとき, 式 ( 8 ) の $\alpha / \beta, c, \alpha, \beta$ の求め方について述べる.

MDE 曲線の最大速度期において式 ( 8 )の第 2 項は

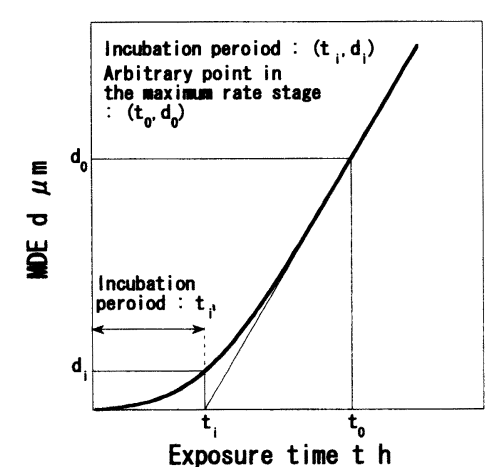

Fig. 3 Schematic diagram of MDE curve 
$t \rightarrow \infty$ のを $e^{-\alpha t} \rightarrow 0$ となるから, MDE 曲線の最大 速度期の直線部は式 $(9$ )で表すことができる.

$$
d=\frac{\alpha}{\beta} t-\frac{1}{\beta} \ln (1+c)
$$

潜伏期 $t_{i}$ は式 (9)に $d=0$ を代入して

$$
t_{i}=\frac{1}{\alpha} \ln (1+c)
$$

となる。

図 4 はこれまでの試験結果から MDE 曲線の最大速 度期の傾きと潜伏期の関係を示したものである. 潜伏 期の長い材料ほど, 最大速度期の傾きが小さく, 両者 の間には

$$
\alpha / \beta=7.72 t_{i}^{-1}
$$

の関係が成り立つ.ここで $A=7.72$ とおくと, 式 (11)は

$$
\beta=\frac{1}{A} \alpha t_{i}
$$

となり, 式(10)を式(12)に代入すると

$$
\beta=\frac{1}{A} \ln (1+c)
$$

となる。

$$
\begin{gathered}
\text { 式(9),(10)より } \\
\qquad d=\frac{\alpha}{\beta}\left(t-t_{i}\right) \cdots
\end{gathered}
$$

が得られる. 式(14)に式(12)を代入すると, 最大速度 期の任意の一点 $\left(t_{0}, d_{0}\right)$ に対して

$$
d_{0}=\frac{\alpha}{\beta} t_{0}-A
$$

となり,これより

$$
\frac{\alpha}{\beta}=\frac{d_{0}+A}{t_{0}}
$$

が得られる. 式(15) は, 最大速度期の任意の一点 $\left(t_{0}\right.$, $\left.d_{0}\right)$ より最大速度期の傾き $\alpha / \beta$ が与えられることを示 している.

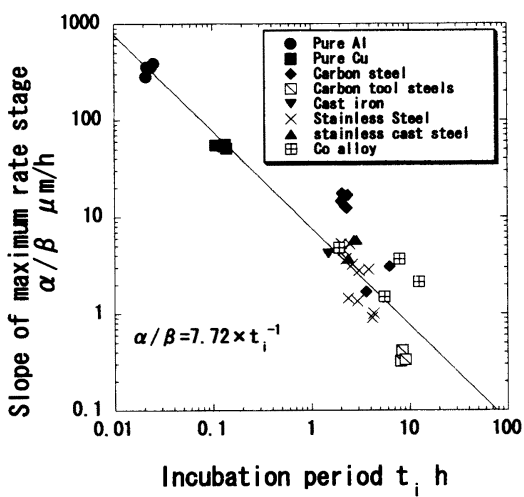

Fig. 4 Relation between incubation period and the slope of maximum rate stage
潜伏期終了時 $\left(t_{i}, d_{i}\right)$ において式(10)，(13)を式 （8）に代入すると

$$
\frac{d_{i}}{A} \ln (1+c)=\ln \frac{1+2 c}{1+c}
$$

が得られる。ここで $1 \ll c$ とすると

$$
c=2^{A / d_{i}}
$$

となる。

図 5 はこれまでの実験により得られている潜伏期終 了時の MDE と潜伏期の関係を示す. 図 5 より潜伏期 終了時の MDEである $d_{i}$ は潜伏期 $t_{i}$ によらずほぼ一 定であることがわかる. $d_{i}$ の平均值は $d_{i}=2.2 \mu \mathrm{m}$ で あるので, この值を式(17)に代入して $c$ の值を得る. また, 式(17)を式(13)に代入することにより $\beta$ の值が 得られる. $\alpha$ の值は式(15)を用いて

$$
\alpha=\frac{\alpha}{\beta} \times \beta
$$

・より得られる。.以上より最大速度期の任意の一点 $\left(t_{0}\right.$, $\left.d_{0}\right)$ が与えられると式(13)，(15)，(17)，(18)を用いる ことによりパラメータ $\alpha, \beta, c$ の値を得ることができ る.

図 2 の曲線は, 図中の矢印の一点 $\left(t_{0}, d_{0}\right)$ を用いて 上述の方法で $\alpha, \beta, c$ の值を求め, これらの数值を式 （８）に代入した計算曲線である。どの材料でも試験時 間の経過に伴う MDEの変化が式 $(8)$ で表示できるこ とがわかる. 表 3 は図 2 の曲線に使用した各パラメー

Table 3 Material parameters

\begin{tabular}{|c|c|c|c|c|c|c|}
\hline & $t_{0} \mathrm{~h}$ & $\sigma_{0} \mu \mathrm{m}$ & $\alpha / \beta \mu \mathrm{m} /$ & $c$ & $\alpha 1 \mathrm{~m}$ & $\beta 1 / \mu \mathrm{m}$ \\
\hline A1070 & 0.08 & 22.5 & 378 & 11.4 & 123.0 & 0.326 \\
\hline C1020 & 0.33 & 11.0 & 56.7 & 11.4 & 18.50 & 0.326 \\
\hline S15C & 4.5 & 27.1 & 7.74 & 11.4 & 2.520 & 0.326 \\
\hline S55C & 9.0 & 9.36 & 1.90 & 11.4 & 0.619 & 0.326 \\
\hline SS400 & 5.0 & 43.8 & 10.3 & 11.4 & 3.360 & 0.326 \\
\hline SK95 & 18 & 4.11 & 0.657 & 11.4 & 0.214 & 0.326 \\
\hline SUS304 & 8.0 & 21.7 & 3.68 & 11.4 & 1.200 & 0.326 \\
\hline SCS3 & 7.0 & 25.2 & 4.70 & 11.4 & 1.530 & 0.326 \\
\hline Puro-C0 & 12 & 8.09 & 1.32 & 11.4 & 0.430 & 0.326 \\
\hline
\end{tabular}

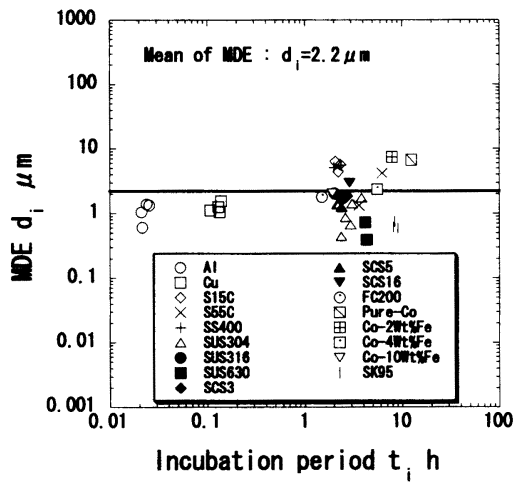

Fig. 5 Relation between incubation period and MDE 
夕である. $\alpha$ は, 単位時間当たりの壊食痕の増殖係数, $\beta$ は壊食痕の合体係数であり, $\alpha / \beta$ は MDE 曲線の最 大速度期のこう配である。 $\beta, c$ は式(13)，(17)より 材料によらず一定值となる.しかし, 図 2(b)におい て, S 15 C や SS 400 の計算曲線が試験初期の実験結 果と少し離れている.

\section{$4 \cdot 3$ 鉄鋼材料のパラメータ $\alpha, \beta, c$ の決定方法}

$4 \cdot 2$ 節で述べた方法により種々の材料の MDE の変化 を式(8)で表示することができた.しかし，SS 400 および S $15 \mathrm{C}$ の計算曲線が試験初期の実験結果を少 し離れていた。これは, 図 4 で, 潜伏期と最大速度期 の傾きの関係を表示する直線に比べて鉄鋼材料の値が やや離れていることによる. 軟質のアルミニウムや純 銅は流体機械材料には一般的に使用されていないの で, $4 \cdot 3$ 節では, 主に鉄鋼材料を対象にして解析した. 図 6 はアルミニウムや純銅を除いた場合の MDE 曲線 の最大速度期の傾きと潜伏期の関係を示したものであ

る. 最大速度期の傾きと潜伏期の間には

$$
\alpha / \beta=33.5 t_{i}^{-2}
$$

の関係が得られる.ここで $B=33.5$ とおくと, 式 (19)は

$$
t_{i}=\sqrt{B \frac{\beta}{\alpha}}
$$

となる. 式(20)を式(14)に代入すると

$$
\frac{\beta}{\alpha} d_{0}=t_{0}-\sqrt{B \frac{\beta}{\alpha}}
$$

が得られる.ここで $\beta / \alpha$ の二次方程式として式(21) を解くと

$$
\frac{\alpha}{\beta}=\frac{2 d_{0}^{2}}{\left(2 d_{0} t_{0}+B\right)-\sqrt{\left(4 d_{0} t_{0}+B\right) B}}
$$

が得られる. 式(22)の分母の根号が正の場合は式(21) の右辺が $t_{0}+\sqrt{B \beta / \alpha}$ の場合に対応するので負の根号 の場合のみを示した.このように最大速度期の傾き

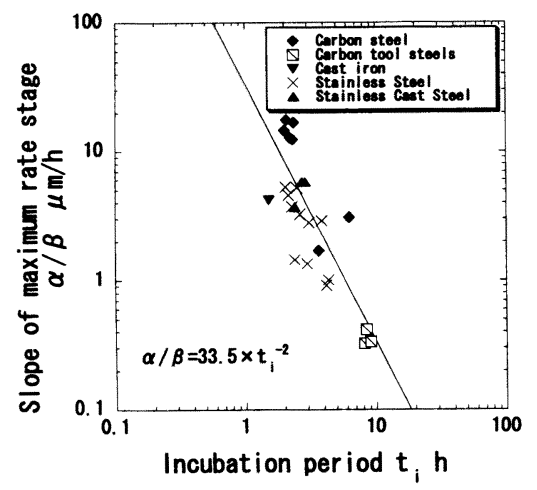

Fig. 6 Relation between incubation period and slope of maximum rate stage $\alpha / \beta$ は最大速度期の任意の一点 $\left(t_{0}, d_{0}\right)$ より求めるこ とができる。

$$
\begin{aligned}
& \text { また, 式 }(10),(20) よ り ~ \\
& \quad \beta=\frac{t_{i}}{B} \ln (1+c) \cdots \cdots \cdots
\end{aligned}
$$

が得られる。潜伏期終了時 $\left(t_{i}, d_{i}\right)$ において式(10), （23）を式（８）に代入すると

$$
\frac{t_{i} d_{i}}{B} \ln (1+c)=\ln \frac{1+2 c}{1+c}
$$

となる.ここで $1 \ll c$ とすると

$$
c=2^{B /\left(t_{i} d_{i}\right)}
$$

である.ここで, $d_{i}$ の值は図 5 において鉄鋼材料のみ の潜伏期終了時の MDE と潜伏期の関係を考えても, 潜伏期終了時の $\mathrm{MDE}$ の平均值が $d_{i}=2.2 \mu \mathrm{m}$ とな る. $t_{i}$ の值は式(22)を式(20)に代入して得る.この $t_{i}, d_{i}$ の值から $c$ の値が求められる。 $\alpha$ は式(18)を用 いて得られる。以上のように最大速度期の任意の一点 $\left(t_{0}, d_{0}\right)$ を用いることで式(18)，(22)，(23)，(25)によ りパラメータ $\alpha, \beta, c$ の值が求められることがわか る.

図 7 の曲線は, 図中の矢印の一点 $\left(t_{0}, d_{0}\right)$ を用いて, 上述の方法で $\alpha, \beta, c$ の值を求め, これらの数值を式 （8）に代入した計算曲線である.どの材料も試験時間 の経過に伴うMDEの変化が式 $(8)$ で表示でき, $4 \cdot 2$ 節の方法よりも試験結果により近い曲線となる。表 4 は図 7 の曲線に使用した各パラメータである.

図 8 は磁わい振動装置による静置試験片法で共振周

Table 4 Material parameters

\begin{tabular}{|c|c|c|c|c|c|c|c|}
\hline & $t_{0} \mathrm{~h}$ & $d_{0} \mu \mathrm{m}$ & $\alpha / \beta \mu \mathrm{m} / \mathrm{h}$ & $\mathrm{t} \mathrm{h}$ & $\mathrm{c}$ & $\alpha 1 \mathrm{~h}$ & $\beta 1 / \mu \mathrm{m}$ \\
\hline S15C & 4.5 & 27.1 & 10.1 & 1.82 & 330 & 3.19 & 0.315 \\
\hline S55C & 9.0 & 9.36 & 1.93 & 4.16 & 12.6 & 0.629 & 0.325 \\
\hline SS400 & 5.0 & 43.8 & 12.9 & 1.61 & 703 & 4.07 & 0.315 \\
\hline SK95 & 18 & 4.11 & 0.442 & 8.71 & 3.36 & 0.169 & 0.383 \\
\hline SUS304 & 8.0 & 21.7 & 4.20 & 2.82 & 42.0 & 1.33 & 0.317 \\
\hline SCS3 & 7.0 & 25.2 & 5.55 & 2.46 & 4.52 & 0.693 & 0.125 \\
\hline
\end{tabular}

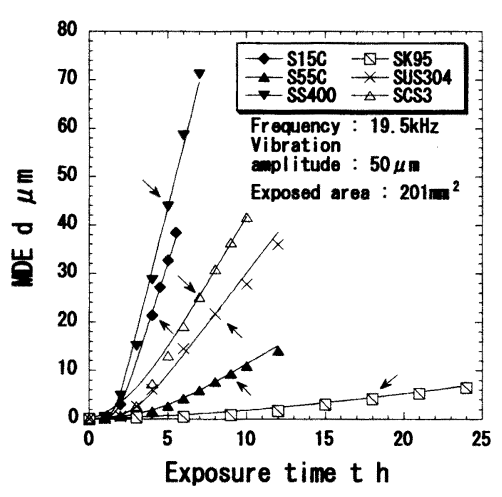

Fig. 7 MDE curves of various materials 
波数が異なる場合, 図 9 は振幅が異なる場合に同様の 方法で曲線を当てはめたものである. 図 10 は試験装 置の違いとして静置試験片法, 振動試験片法, キャビ テーション噴流法の結果を比較したものである. 図 8〜10 亿示すように試験条件や試験方法が異なる場合 でも式（８）を用いて MDE 曲線を表すことができる. 最大速度期中の任意の一点 $\left(t_{0}, d_{0}\right)$ は図 8 10 中の矢 印の点を用いた。表 5〜7 は図 8〜10 の曲線に使用し た各パラメータである.なお, 表 5 中の $f$ は共振周波 数を, 表 6 中の $A$ は振動振幅を表す. 表 7 中の $\mathrm{S}$ は 静置試験片法, $\mathrm{V}$ は振動試験片法, C はキャビテーシ ヨン噴流法を表す， $\alpha / \beta$ の值は振動振幅が大きく, 共 振周波数が大きいものほど大きくなっている.また， 振動試験片法のほうが静置試験片法よりも $\alpha / \beta$ の值 が大きくなっている. 磁わい振動方式と噴流法では直 接的には比較できないが今回の条件ではキャビテーシ ヨン噴流法の方が $\alpha / \beta$ の值が大きい.

以上の上うに材料, 試験条件, 試験方法を問わず, 最大速度期の任意の一点 $\left(t_{0}, d_{0}\right)$ がわかれば式 $(8)$ に より MDE の挙動を表示できることが明らかになっ た.

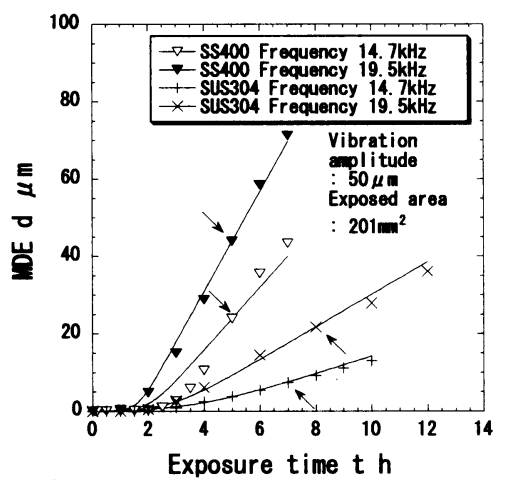

Fig. 8 MDE curves at different frequency

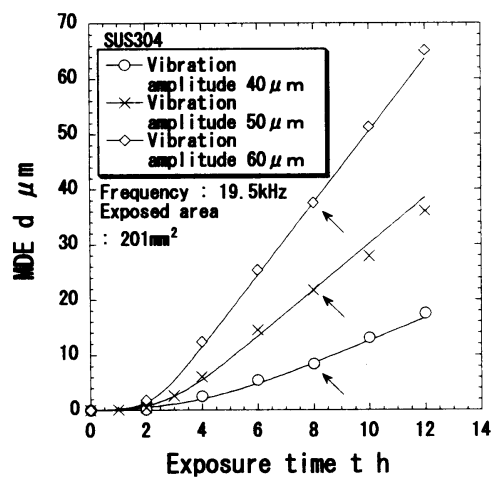

Fig. 9 MDE curves at variaus vibration amplitudes

\section{5. 結言}

本研究では, 前報(6) で提案した壊食過程の表示式の パラメータ数を少なくする方法を考案し, 種々の材料, 試験方法, 試験条件の実験結果に対する適用性につい て検討した。その結果, 以下の点が明らかになった。

（1） キャビテーション壊食過程におけるMDE 曲 線の挙動は, ロジスティック曲線を積分した次式で与 えられる。

$$
d=\frac{\alpha}{\beta} t-\frac{1}{\beta} \ln \frac{1+c}{1+c e^{-\alpha t}}
$$

ただし, $\alpha, \beta, c$ は定数である.

（2）純アルミニウムおよび純銅を含めた一般材料 の $\mathrm{MDE}$ 曲線の最大速度期の傾き $\alpha / \beta$ と潜伏期 $t_{i}$ に は関係 $\alpha / \beta \propto t^{-1}$ の関係がある.鉄鋼材料のみでは

Table 5 Parameters at different frequency

\begin{tabular}{|c|c|c|c|c|c|c|c|}
\hline & $t_{0} \mathrm{~h}$ & $\phi_{0} \mu \mathrm{m}$ & $\alpha / \beta \mu \mathrm{m} / \mathrm{h}$ & $4 \mathrm{~h}$ & c & $a 1 \mathrm{~h}$ & $\beta_{1 / \mu m}$ \\
\hline $4.7 \mathrm{kHz}$ & 5.0 & 23.9 & 8.07 & 2.04 & 178 & 2.54 & 0.315 \\
\hline $\begin{array}{c}\mathbf{S} \\
\mathrm{f}=19 \mathrm{C} \mathrm{K} \mathrm{kZ}\end{array}$ & 6.0 & 2.02 & 1.53 & 4.68 & 9.54 & 0.503 & 0.329 \\
\hline $\begin{array}{c}\text { SUS } 304 \\
t=147 \mathrm{KHZ}\end{array}$ & 7.0 & 7.37 & 2.31 & 3.81 & 16.0 & 0.743 & 0.322 \\
\hline $\begin{array}{c}\text { SUS304 } \\
\mathrm{f}=19.5 \mathrm{kHz}\end{array}$ & 8.0 & 21.7 & 4.20 & 2.82 & 42.0 & 1.33 & 0.317 \\
\hline
\end{tabular}

Table 6 Parameters at various amplitudes

\begin{tabular}{|c|c|c|c|c|c|c|c|}
\hline & $t_{\mathrm{h}} \mathrm{h}$ & $d_{0} \mu \mathrm{m}$ & $\alpha / \beta \mu \mathrm{m} / \mathrm{h}$ & $\mathrm{t}_{\mathrm{h}}$ & $\mathrm{c}$ & $\alpha 1 \mathrm{~h}$ & $\beta 1 / \mathrm{mm}$ \\
\hline $\begin{array}{c}\text { SUS304 } \\
A=40 \mu \mathrm{m}\end{array}$ & 8.0 & 8.35 & 2.09 & 4.00 & 14.0 & 0.675 & 0.323 \\
\hline $\begin{array}{c}S U S 304 \\
A=50 \mu \mathrm{m}\end{array}$ & 8.0 & 21.7 & 4.20 & 2.82 & 42.0 & 1.33 & 0.317 \\
\hline $\begin{array}{c}S U S 304 \\
A=60 \mu \mathrm{m}\end{array}$ & 8.0 & 37.5 & 6.54 & 2.26 & 107 & 2.07 & 0.316 \\
\hline
\end{tabular}

Table 7 Parameters of various test methods

\begin{tabular}{|c|c|c|c|c|c|c|c|}
\hline & $t_{0} \mathrm{~h}$ & $d_{0} \mu \mathrm{m}$ & $\alpha / \beta \mu \mathrm{m} / \mathrm{h}$ & $4 \mathrm{~h}$ & $\mathrm{c}$ & $\mathrm{a} 1 \mathrm{~h}$ & $\beta 1 / \mu \mathrm{m}$ \\
\hline SUS304-S & 8.0 & 21.7 & 4.20 & 2.82 & 42.0 & 1.33 & 0.317 \\
\hline SUS304-V & 4.0 & 38.0 & 15.1 & 1.49 & 1204 & 4.77 & 0.315 \\
\hline SUS304-C & 8.0 & 70.3 & 11.2 & 1.73 & 448 & 3.53 & 0.315 \\
\hline
\end{tabular}

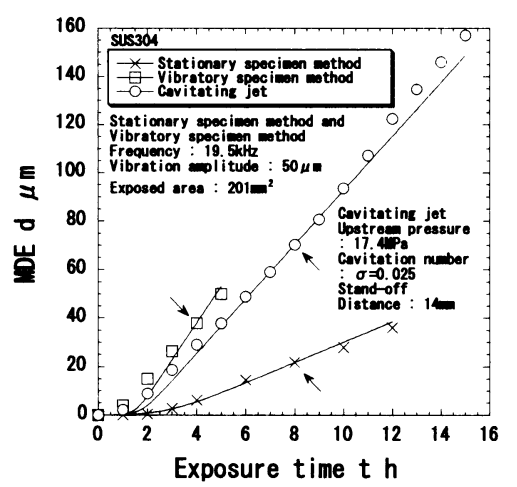

Fig. 10 MDE curves of various test methods 
$\alpha / \beta \propto t^{-2}$ となる。

（3） MDE 曲線の潜伏期終了時の MDE は潜伏期 $t_{i}$ によらず $2.2 \mu \mathrm{m}$ である.

(4) $\mathrm{MDE}$ 曲線の最大速度期の任意の一点 $\left(t_{0}, d_{0}\right)$ がわかれば, 結言 (2)，（3)を用いて, 結言(1)の $\mathrm{MDE}$ 曲線のパラメータ $\alpha, \beta, c$ を求めることができ る.

（5）得られたパラメータ $\alpha, \beta, c$ の值を用いて計 算した曲線は, 実験結果の傾向とよく一致する.

\section{文献}

(1) Kato, H., Int. Shipbbuild. Prog., 22-253 (1975), 305-327.
(2) Rao, P. V. and Buckley, D. H., Wear, 94 (1984), 259274.

(3) Karimi, A. and Maamouri, M., Proc. 7th Int. Conf. on Erosion by Liquid and Solid Impact, (1987), 27-1-278.

(4) Karimi, A. and Leo, W. R., Mater. Sci. Eng., 95 (1987), 1-14.

( 5 ) Karimi, A., 2nd Int. Symp. Cavitation, (1994), 231-236

（6）服部修次 - 前田浩平, 機論, 70-691, A (2004), 182-187.

(7) ASTM Designation G 32-98, Annual Book of ASTM Standards, (2000), 107-120.

(8) ASTM Designation G 134-95, Annual Book of ASTM Standards, (2000), 61-572. 